\title{
Gastrointestinal Stromal Tumours of the Small Intestine
}

\author{
Hakan Uzunoglu, Yasin Tosun, Ozan Akinci and Baver Baris \\ Department of General Surgery, Kartal Dr. Lütfi Kırdar City Hospital, Istanbul, Turkey
}

\begin{abstract}
Objectives: To describe the spectrum of small intestine gastrointestinal stromal tumour (GIST) cases; and to analyse prognostic factors.

Study Design: Descriptive study.

Place and Duration of Study: Kartal Dr. Lütfi Kirdar City Hospital, Istanbul, Turkey, from 2010 to 2020.

Methodology: Forty patients with small intestine GIST followed up between 2010-2020 were included in this study. The demographic information and clinical laboratory, histopathology, and radiology findings of all patients were analysed and compared. Five-year overall survival (OS) rate and five-year disease-free survival (DFS)were calculated.

Results: The mean patient age at diagnosis was $58.9 \pm 12.6$ years (34-79 years). Thirty-seven (92.5\%) tumours were in the jejunum and ileum, and three (7.5\%) were in the duodenum. The most common symptoms were bleeding (50\%) and pain (37.5\%). A total of $5 \%$ of the patients were asymptomatic, and $67.5 \%$ were in the high-risk group. Two patients (5\%) died within a 30-day postoperative period, and 13 (32.5\%) died during the follow-up period. The five-year overall survival (OS) rate was $54.2 \%$. The mean five-year OS and five-year disease-free survival (DFS) were $47.5 \pm 16.8$ months and $40.9 \pm 25.0$ months, respectively. The mortality risk was calculated as 4.5-fold increased in the patients aged over 60 years and as 3.556 -fold increased in those with recurrence/metastasis detected in their follow-ups.

Conclusion: The OS ratio and OS duration were not as high as expected for small intestine GIST cases. Tumour diameter, mitotic index, and risk classification may not provide sufficient information for prognosis prediction in some cases. The frequency of recurrence and/or metastasis was higher than expected - although complete resection was achieved.
\end{abstract}

Key Words: Gastrointestinal stromal tumours, Small intestine, Tumour diameter, Mitotic index.

How to cite this article: Uzunoglu H, Tosun Y, Akinci O, Baris B. Gastrointestinal Stromal Tumours of the Small Intestine. J Coll Physicians Surg Pak 2021; 31(12):1487-1493.

\section{INTRODUCTION}

Gastrointestinal stromal tumours (GIST) are the most common mesenchymal tumours. GISTs originate from the precursors of the interstitial cells of cajal. The incidence of GIST is between 4.3-15 per million. GISTs most commonly involve the stomach followed by the small intestine. ${ }^{1-3}$ In most GIST cases, diagnosis is made via the histopathological examination of the resection material removed during the operation. In some cases, diagnosis is made via the pathological examination of the pre-op biopsy sample collected with aspiration, under the guidance of endoscopic ultrasonography. However, this method may cause complications, such as perforation or bleeding. ${ }^{1-5}$

The most common treatment performed in small intestine GIST cases is the surgical resection of the tumour, which is the aim of removing the tumour completely.

Correspondence to: Dr. Hakan Uzunoglu, Department of General Surgery, Kartal Dr. Lutfi Kirdar City Hospital, Istanbul, Turkey

E-mail: drhakanuzunoglu@gmail.com

Received: October 02, 2020; Revised: November 25, 2020;

Accepted: December 22, 2020

DOI: https://doi.org/10.29271/jcpsp.2021.12.1487
However, despite complete resection, recurrences can be seen frequently in the first two years after surgery. However, in some cases featuring a large tumour or with high risk of recurrence, adjuvant chemotherapy consisting tyrosine kinase inhibitors (i.e., imatinib) is given to the patient to facilitate a better outcome. The prognosis is very variable in GIST cases. Some small intestine GIST cases may have a very good clinical course. However, in many cases, the clinical picture can deteriorate rapidly, and morbidity and mortality can occur despite surgical treatment. ${ }^{3-6}$ Therefore, predicting prognosis is critical in small intestine GISTs. In order to determine the prognosis, various risk classifications have been made, in which the localisation, diameter, and mitotic activity of the primary tumour are evaluated together. ${ }^{3,7,8}$

In small intestine GIST cases, early diagnosis and follow-up are critical. Recurrence or metastasis can be most commonly seen in the liver, periton, or resection area in small intestine GIST cases. In order to avoid complications, morbidity, recurrence and metastasis during follow-up, the patient should be followed closely for a long time aftersurgery. ${ }^{9-12}$

There have only been a few studies conducted specifically on small intestine GIST cases. ${ }^{13-19}$ In this study, the aim was to analyse the clinical, laboratory, pathological and radiological 
findings of small intestine GIST cases, followed up for ten years at this hospital as well as to analyse the prognostic factors.

\section{METHODOLOGY}

This study was performed in line with the principles of the Declaration of Helsinki. Ethical approval was waived by the local Ethics Committee in view of the retrospective nature of the study and all the procedures being performed were part of the routine care (Date: 08/07/2020; No. 2020/514/181/12).

A total of 40 patients who were operated upon dueto small intestine GISTs in the General Surgery Department, Kartal Dr. Lütfi Kirdar City Hospital, Istanbul, Turkey within the 10-year period between May 2010 and May 2020, were included in this study. The demographic information and clinical, laboratory, pathology, and radiology findings of all the patients were recorded. Those who refused to participate, those under the age of 18 years, and those who died due to a cause other than the small intestine GIST tumour, were not included in this study. Risk classification of the patients was grouped, based on the National Institute of Health $(\mathrm{NIH})$ prognostic criteria developed according to the tumour diameters and mitotic indexes. ${ }^{3,7,8}$

The tumours were excised and the biopsy samples were collected with aspiration under the guidance of endoscopic ultrasonography.

All statistical analyses were done using SPSS version 25.0 software (IBMSPSS, Chicago, IL, USA). Qualitative data are given as numbers and percentages; while, quantitative as mean \pm standard deviation. In terms of categorical variables, comparisons between groups were made with Pearson's Chi-square, likelihood ratio or Fisher's Exact test. Whether continuous variables are suitable for normal distribution was confirmed by the Shapiro-Wilk test. A kurtosis value \pm 1.0 was considered excellent and a value between \pm 2.0 was also acceptable, The differences between the groups in terms of continuous variables were analysed using Student's t-test, and the comparison of mean values was done between multiple groups by variance analysis. The relationship between continuous variables was tested using Pearson's correlation analysis. Risk coefficient of categorical variables was evaluated by logistic regression analysis and given as odds ratio. The results were evaluated within the $95 \%$ confidence interval, and $p<0.05$ values were considered significant. Bonferroni correction was made wherever appropriate.

\section{RESULTS}

Twenty-one (52.5\%) patients were males. A total of 37 (92.5\%) of the tumours were in the jejunum and ileum, and three $(7.5 \%)$ were in the duodenum. The most common symptoms were bleeding (50\%) and pain (37.5\%). The tumour diameter was 10 $\mathrm{cm}$ and greater in $37.5 \%$ of the patients, the mitotic index was 5 150 high power field (HPF) and below in $62.5 \%$. A total of $67.5 \%$ patients were in the high-risk group. $\mathrm{CD} 117$ and DOG1 were detected in all patients, and CD34 in 77.5\% (Table I).
Table I: Distribution of symptoms, risk, tumour diameter, mitotic index groups and markerdetection rates.

\begin{tabular}{|c|c|c|}
\hline & $\mathbf{n}$ & $\%$ \\
\hline \multicolumn{3}{|l|}{ Gender } \\
\hline Men & 21 & 52.5 \\
\hline Women & 19 & 47.5 \\
\hline \multicolumn{3}{|l|}{ Localization } \\
\hline Jejunum and ileum & 37 & 92.5 \\
\hline Duodenum & 3 & 7.5 \\
\hline \multicolumn{3}{|l|}{ Symptoms } \\
\hline Bleeding & 20 & 50.0 \\
\hline Pain & 15 & 37.5 \\
\hline Palpable mass & 2 & 5.0 \\
\hline Asymptomatic & 2 & 5.0 \\
\hline Other & 1 & 2.5 \\
\hline \multicolumn{3}{|l|}{ Diagnosis type } \\
\hline Resection material & 39 & 97.5 \\
\hline Pre-op biopsy & 1 & 2.5 \\
\hline Additional disease & 19 & 47.5 \\
\hline $\mathrm{HT}$ & 9 & 22.5 \\
\hline DM & 8 & 20.0 \\
\hline $\mathrm{DM}+\mathrm{HT}$ & 1 & 2.5 \\
\hline Other & 1 & 2.5 \\
\hline \multicolumn{3}{|l|}{$\mathrm{NIH}$ risk category } \\
\hline Very Low & 0 & 0 \\
\hline Low & 9 & 22.5 \\
\hline Intermediate & 4 & 10.0 \\
\hline High & 27 & 67.5 \\
\hline \multicolumn{3}{|c|}{ Tumour diameter $(\mathrm{cm})$} \\
\hline$\leq 2$ & 1 & 2.5 \\
\hline $2.01-5$ & 12 & 30.0 \\
\hline $5.01-9.99$ & 12 & 30.0 \\
\hline$\geq 10$ & 15 & 37.5 \\
\hline$\leq 5$ & 13 & 32.5 \\
\hline$>5$ & 27 & 67.5 \\
\hline \multicolumn{3}{|c|}{ Mitotic index (/50HPF) } \\
\hline$\leq 5$ & 25 & 62.5 \\
\hline $5.01-9.99$ & 2 & 5.0 \\
\hline$\geq 10$ & 13 & 32.5 \\
\hline$\leq 5$ & 25 & 62.5 \\
\hline$>5$ & 15 & 37.5 \\
\hline CD117 & 40 & 100.0 \\
\hline CD34 & 31 & 77.5 \\
\hline DOG 1 & 25 & $100 *$ \\
\hline S100 & 2 & 5.0 \\
\hline Desmin & 1 & 2.5 \\
\hline Necrosis & 24 & 60.0 \\
\hline Rupture & 8 & 20.0 \\
\hline
\end{tabular}

The mortality rate was significantly higher in the patients over 60 years $(p=0.033)$. Comparisons between the patients and survivors, as well as risk analyses of the patients, are shown in Tablell.

The mean DFS was significantly lower in the patients with a tumour diameter $>5 \mathrm{~cm}(32.3 \pm 35.5$ months) than those with a tumour diameter of $\leq 5 \mathrm{~cm}(60.9 \pm 37.8$ months) $(p=0.024)$. In addition, the mean DFS in those in the high-risk category ( $32 \pm 35.8$ months) was significantly lower compared to that of the patients in the non-high-riskgroups ( $61.5 \pm 36.6$ months) $(p=0.02)$ (Table III).

Seven (17.5\%) patients had metastases at the time of diagnosis, and $12(30 \%)$ had metastasis or recurrence detected during follow-up. 
Table II: Comparison and risk analysis in terms of mortality.

\begin{tabular}{|c|c|c|c|c|c|c|c|c|}
\hline & \multicolumn{2}{|c|}{ Died } & \multicolumn{2}{|c|}{ Alive } & \multirow{2}{*}{$\begin{array}{l}\text { Total } \\
n=40\end{array}$} & \multirow{2}{*}{$\mathbf{p}^{*}$} & \multirow{2}{*}{$\mathbf{O R}^{* *}$} & \multirow{2}{*}{$(95 \% \mathrm{Cl})$} \\
\hline & $n=13$ & $\%$ & $\mathbf{n}=\mathbf{2 7}$ & $\%$ & & & & \\
\hline Gender (male) & 4 & 30.8 & 17 & 63.0 & 21 & 0.056 & 0.261 & $0.064-1.074$ \\
\hline Age at diagnosis ( $>60$ years) & 9 & 69.2 & 9 & 33.3 & 18 & 0.033 & 4.5 & $1.084-18.689$ \\
\hline Necrosis & 9 & 69.2 & 15 & 55.6 & 24 & 0.408 & 1.8 & $0.443-7.308$ \\
\hline Rupture & 2 & 15.4 & 6 & 22.2 & 8 & $>0.999$ & 0.636 & $0.11-3.694$ \\
\hline R0 resection & 10 & 76.9 & 21 & 77.8 & 31 & $>0.999$ & 0.952 & $0.197-4.611$ \\
\hline Second primary tumour & 2 & 15.4 & 1 & 3.7 & 3 & 0.242 & 4.727 & $0.387-57.696$ \\
\hline Recurrence-metastasis during follow-up & 4 & 30.8 & 3 & 11.1 & 7 & 0.187 & 3.556 & $0.662-19.108$ \\
\hline $\mathrm{NIH}$ risk category & & & & & & 0.674 & & \\
\hline Very Low & 0 & 0 & 0 & 0 & 0 & & & \\
\hline Low & 2 & 15.4 & 7 & 25.9 & 9 & & & \\
\hline Intermediate & 1 & 7.7 & 3 & 11.1 & 4 & & & \\
\hline High & 10 & 76.9 & 17 & 63.0 & 27 & & & \\
\hline Not High & 3 & 23.1 & 10 & 37.0 & 13 & & & \\
\hline High & 10 & 76.9 & 17 & 63.0 & 27 & 0.484 & 1.961 & $0.434-8.86$ \\
\hline Tumour diameter $(\mathrm{cm})$ & & & & & & 0.163 & & \\
\hline$\leq 2$ & 0 & 0.0 & 1 & 3.7 & 1 & & & \\
\hline $2.01-5$ & 3 & 23.1 & 9 & 33.3 & 12 & & & \\
\hline $5.01-9.99$ & 2 & 15.4 & 10 & 37.0 & 12 & & & \\
\hline$\geq 10$ & 8 & 61.5 & 7 & 25.9 & 15 & & & \\
\hline$\leq 5$ & 3 & 23.1 & 10 & 37.0 & 13 & 0.484 & 1.961 & $0.434-8.86$ \\
\hline$>5$ & 10 & 76.9 & 17 & 63.0 & 27 & & & \\
\hline Mitotic Index (/50HPF) & & & & & & 0.555 & & \\
\hline$\leq 5$ & 8 & 61.5 & 17 & 63.0 & 25 & & & \\
\hline $5.01-9.99$ & 0 & 0.0 & 2 & 7.4 & 2 & & & \\
\hline$\geq 10$ & 5 & 38.5 & 8 & 29.6 & 13 & & & \\
\hline$\leq 5$ & 8 & 61.5 & 17 & 63.0 & 25 & & & \\
\hline$>5$ & 5 & 38.5 & 10 & 37.0 & 15 & $>0.999$ & 1.063 & $0.272-4.153$ \\
\hline
\end{tabular}

Two patients (5\%) died within the post-op 30-day period, and $13(32.5 \%)$ died during the follow-up period. Five-year OS and 5 -year DFS rates were both $54.2 \%$ in the patients.

The mean of the patients age at diagnosis was $58.9 \pm 12.6$ years (age range: $34-79$ years). The mean follow-up period of the patients was $46.03 \pm 35.8$ months. The mean tumour diameter was $8.3 \pm 4.6 \mathrm{~cm}$ (range: $2.0-19.5 \mathrm{~cm}$ ), and the mean mitotic index was $11.9 \pm 20.8 / 50 \mathrm{HPF}$ (range: $1-115 / 50 \mathrm{HPF}$ ). The mean 5-year OS of the patients was $47.5 \pm 16.8$ months, and the mean 5-year DFS was $40.9 \pm 25.0$ months. The mean OS of the patients was $47.4 \pm 34.4$ months, and the mean overall DFS was $41.6 \pm 38.3$ months.

The five-year OS decreased as the patient age increased $(p=0.027 ; r=-0.45)$. Risk levels were significantly correlated with tumour diameter $(p<0.001 ; r=0.664)$ and inversely correlated with overall DFS $(p=0.041 ; r=-0.325)$. Tumour diameter was inversely correlated with overall DFS $(p=0.026 ; r=-0.352)$.

\section{DISCUSSION}

Gastric and small intestine GIST cases are known to be similar in terms of their clinical features and prognosis. However, it has been stated that there may be differences between gastric and small intestine GISTs in terms of tumour diameter, mitotic index, prognosis, OS, and DFS. ${ }^{3-8}$ Therefore, separately reviewing small intestine GIST cases can provide useful information in terms of determination of the prognosis. In the present study, only small intestine GIST cases were examined, and the effects of symptoms and findings on prognosis were evaluated.

The most common symptoms in small intestine GIST cases are bleeding, abdominal pain, and anemia. ${ }^{13,14}$ In the present study, most of the patients $(87.5 \%)$ presented with bleeding and/or pain, and $5 \%$ of the patients were found to be asymptomatic. It has been reported that small intestine GISTs are seen more frequently in those aged 60 and older. ${ }^{13,15}$

Table III: Comparison of mean survival duration by tumour diameter, mitotic index and risk groups.

\begin{tabular}{|c|c|c|c|c|c|c|c|c|c|c|}
\hline & \multicolumn{2}{|c|}{ 5-year OS rate } & \multicolumn{2}{|c|}{$\begin{array}{c}\text { 5-Year-Overall survival } \\
\text { (months) }\end{array}$} & \multicolumn{2}{|c|}{$\begin{array}{c}\text { 5-Year-DFS survival } \\
\text { (months) }\end{array}$} & \multicolumn{2}{|c|}{$\begin{array}{c}\text { Overall survival } \\
\text { (months) }\end{array}$} & \multicolumn{2}{|c|}{$\begin{array}{c}\text { Disease-free survival } \\
\text { (months) }\end{array}$} \\
\hline & $n=13(\%)$ & p* & Mean \pm SD & p** & Mean \pm SD & $\mathbf{p}^{* *}$ & Mean \pm SD & p** & Mean \pm SD & $\mathbf{p}^{* *}$ \\
\hline Gender & & 0.219 & & 0.073 & & 0.35 & & 0.235 & & 0.344 \\
\hline
\end{tabular}




\begin{tabular}{|c|c|c|c|c|c|c|c|c|c|c|}
\hline Men & $8(61.5)$ & & $53.8 \pm 11.1$ & & $45.8 \pm 24.6$ & & $53.6 \pm 32.5$ & & $47.1 \pm 37.9$ & \\
\hline Women & $5(38.5)$ & & $41.3 \pm 19.6$ & & $36 \pm 25.4$ & & $40.5 \pm 36$ & & $35.5 \pm 38.7$ & \\
\hline Age at diagnosis & & 0.107 & & 0.105 & & 0.127 & & 0.258 & & 0.242 \\
\hline$\leq 60$ years & $9(69.2)$ & & $52.7 \pm 14.4$ & & $48.1 \pm 21.6$ & & $53 \pm 32.3$ & & $48 \pm 36.4$ & \\
\hline$>60$ years & $4(30.8)$ & & $41.5 \pm 18.1$ & & $32.4 \pm 27.0$ & & $40.5 \pm 36.5$ & & $33.7 \pm 40$ & \\
\hline Tumour diameter $(\mathrm{cm})$ & & 0.022 & & 0.343 & & 0.149 & & 0.139 & & 0.077 \\
\hline$\leq 2$ & $1(7.7)$ & & $60 \pm 0$ & & $60 \pm 0$ & & $109 \pm 0$ & & $109 \pm 0$ & \\
\hline $2.01-5$ & $5(38.5)$ & & $44.3 \pm 21.9$ & & $44.3 \pm 21.9$ & & $56.9 \pm 36.5$ & & $56.9 \pm 36.5$ & \\
\hline $5.01-9.99$ & $4(30.8)$ & & $60 \pm 0$ & & $60 \pm 0$ & & $36.6 \pm 37.1$ & & $34.1 \pm 39$ & \\
\hline$\geq 10$ & $3(23.1)$ & & $44.3 \pm 14.8$ & & $29.7 \pm 27.7$ & & $44.3 \pm 26.5$ & & $30.8 \pm 33.7$ & \\
\hline Tumour diameter $(\mathrm{cm})$ & & 0.423 & & 0.762 & & 0.448 & & 0.083 & & 0.024 \\
\hline$\leq 5$ & $6(46.2)$ & & $46 \pm 21.2$ & & $46 \pm 21.2$ & & $60.9 \pm 37.8$ & & $60.9 \pm 37.8$ & \\
\hline$>5$ & $7(53.8)$ & & $48.5 \pm 14.4$ & & $37.8 \pm 27.2$ & & $40.9 \pm 31.2$ & & $32.3 \pm 35.5$ & \\
\hline Mitotic index (/50HPF) & & 0.526 & & 0.708 & & 0.587 & & 0.891 & & 0.967 \\
\hline$\leq 5$ & $8(61.5)$ & & $48.1 \pm 17.6$ & & $42.8 \pm 24.2$ & & $46.8 \pm 33.5$ & & $42.8 \pm 36.3$ & \\
\hline 5.01-9.99 & $1(7.7)$ & & $60 \pm 0$ & & $60 \pm 0$ & & $37.5 \pm 48.8$ & & $37.5 \pm 48.8$ & \\
\hline$\geq 10$ & $4(30.8)$ & & $45 \pm 16.7$ & & $34.9 \pm 27.9$ & & $49.9 \pm 37$ & & $39.9 \pm 43.8$ & \\
\hline Mitotic index (/50HPF) & & $>0.999$ & & 0.849 & & 0.636 & & 0.901 & & 0.804 \\
\hline$\leq 5$ & $8(61.5$ & & $48.1 \pm 17.6$ & & $42.8 \pm 24.2$ & & $46.8 \pm 33.5$ & & $42.8 \pm 36.3$ & \\
\hline$>5$ & $5(38.5)$ & & $46.7 \pm 16.4$ & & $37.7 \pm 27.4$ & & $48.3 \pm 36.9$ & & $39.6 \pm 42.6$ & \\
\hline $\mathrm{NIH}$ risk category & & 0.397 & & 0.972 & & 0.57 & & 0.173 & & 0.062 \\
\hline Very Low & - & & - & & - & & - & & - & \\
\hline Low & $4(30.8)$ & & $46.3 \pm 21.4$ & & $46.3 \pm 21.4$ & & $58.3 \pm 38.2$ & & $58.3 \pm 38.2$ & \\
\hline Intermediate & $3(23.1)$ & & $49 \pm 22$ & & $49 \pm 22$ & & $68.8 \pm 36.9$ & & $68.8 \pm 36.9$ & \\
\hline High & $6(46.2)$ & & $47.6 \pm 14.6$ & & $36.2 \pm 27.5$ & & $40.6 \pm 31.7$ & & $32 \pm 35.8$ & \\
\hline $\mathrm{NIH}$ risk category & & 0.24 & & 0.973 & & 0.266 & & 0.07 & & 0.02 \\
\hline Not High & $7(53.8)$ & & $47.4 \pm 20.4$ & & $47.4 \pm 20.4$ & & $61.5 \pm 36.6$ & & $61.5 \pm 36.6$ & \\
\hline High & $6(46.2)$ & & $47.6 \pm 14.6$ & & $36.2 \pm 27.5$ & & $40.6 \pm 31.7$ & & $32 \pm 35.8$ & \\
\hline Necrosis & & 0.423 & & 0.945 & & 0.438 & & 0.832 & & 0.825 \\
\hline Present & $7(53.8)$ & & $47.7 \pm 15.8$ & & $37.7 \pm 27.3$ & & $48.3 \pm 36.2$ & & $40.5 \pm 41.5$ & \\
\hline Absent & $6(46.2)$ & & $47.2 \pm 19.5$ & & $46.1 \pm 21$ & & $45.9 \pm 32.6$ & & $43.3 \pm 34.1$ & \\
\hline Rupture & & 0.458 & & 0.109 & & 0.095 & & 0.053 & & 0.074 \\
\hline Present & 0.0 & & $21 \pm 0$ & & $0 \pm 0$ & & $26.5 \pm 21.1$ & & $20 \pm 25.5$ & \\
\hline Absent & $13(100.0)$ & & $48.7 \pm 16.2$ & & $42.7 \pm 23.9$ & & $52.6 \pm 35.3$ & & $47 \pm 39.3$ & \\
\hline R0 Resection & & $>0.999$ & & 0.822 & & 0.924 & & 0.294 & & 0.247 \\
\hline Yes & $11(84.6)$ & & $47.9 \pm 17.3$ & & $41.1 \pm 25.8$ & & $50.5 \pm 35.2$ & & $45.4 \pm 38.7$ & \\
\hline No & $2(15.4$ & & $45.8 \pm 16.9$ & & $39.8 \pm 23.5$ & & $36.7 \pm 30.8$ & & $28.4 \pm 35.8$ & \\
\hline Additional disease & & $>0.999$ & & 0.836 & & 0.564 & & 0.247 & & 0.531 \\
\hline Absent & $9(69.2)$ & & $48.1 \pm 16.6$ & & $38.9 \pm 27.5$ & & $54.1 \pm 35.1$ & & $45.6 \pm 41.5$ & \\
\hline Present & $4(30.8)$ & & $46.5 \pm 18.4$ & & $44.8 \pm 20.1$ & & $41.3 \pm 33.4$ & & $37.9 \pm 35.7$ & \\
\hline
\end{tabular}

In the present study, it was observed that the number of the cases were found to be slightly higher in those of the 6th and 7 th decades and the males. It should also be kept in mind that patients of an advanced age who have complaints of pain and bleeding may have small intestine GIST.

The purpose of GIST surgery is to provide complete resection to reduce the possibility of recurrence and the development of metastasis. It has been reported that complete resection affects prognosis in GIST cases. ${ }^{5,6,10}$ Crosby et al. reported that complete resection was achieved in $70 \%$ of the patients. ${ }^{15}$ Complete resection rate was $77.5 \%$ in this study. These findings show that the rate of complete resection is not very high in small intestine GIST cases. Additionally, Crosby et al. detected metastases in $18 \%$ of their patients at the time of diagnosis. ${ }^{15}$ These researchers showed that $11 \%$ of the patients who underwent complete resection developed metastasis and that complete resection significantly affected their prognosis. In their meta-analysis, Machairas et al. determined that the rate of recurrence in patients undergoing complete resection varied between $20-50 \% .{ }^{20}$ In the literature, recurrence and/or metastasis rates were reported to be between $22-48 \% .{ }^{13-15}$ In the present study, metastasis was detected in $17.5 \%$ of the patients at the time of diagnosis, and metastasis or recurrence was detected in $30 \%$ of the patients during the follow-up period. Complete resection rates were similar between the patients who died and those who survived during the follow-up period. In addition, the five-year OS rate, five-year OS duration, five-year DFS rate, and overall DFS values were all similar among the patients who underwent complete resection and those for whom the tumour could not be resected completely. All these data show that complete resection cannot be achieved in all small intestine GIST cases, and the rate of recurrence or metastasis development is not very low in patients who underwent complete resection.

In the present study, no significant difference was found 
between the patients who died during the follow-up period and those who survived in terms of recurrence/metastasis rates. However, in the present study, it was determined that those who had recurrence/metastasis in their follow-ups had a 3.556-fold increased risk of mortality. This finding shows the importance of close follow-up with patients in terms of the development of recurrence or metastasis.

The mortality rate for small intestine GIST cases has been reported to be between $11.8-72 \% .{ }^{13,15,16,21}$ The five-year OS rate has been reported to be between $41-87.5 \% .{ }^{13-15,21}$ In their review, Machairas et al. determined that the five-year OS rate varied between $30-65 \%$ in patients who underwent complete resection. ${ }^{20}$ Crosby et al. reported that the mean OS duration was significantly higher in those who underwent complete resection. ${ }^{15}$ In the present study, the mean fiveyear OS of the patients was $47.5 \pm 16.8$ months, and the five-year DFS was $40.9 \pm 25.0$ months. The mean OS of the patients was $47.4 \pm 34.4$ months, and the mean DFS was $41.6 \pm 38.3$ months. These findings show that the mortality rate can be high and the overall survival and five-year OS rates not very high despite complete resection in small intestine GIST cases.

Fan et al. and Wu et al. found that the mean DFS values were similar between patients over 60 years-old and those under $60 .{ }^{17,18}$ In the present study, the patients over 60 years and those below 60 years also had similar mean OS and fiveyear OS values. However, in the present study, the five-year OS was significantly correlated with age. In addition, mortality was significantly higher among the patients over 60 years of age. In the risk analysis, the mortality risk was calculated as 4.5-fold increased in those over 60 years of age. This data shows that age has an effect on prognosis, but taking a different threshold for age may be more decisive in terms of prognosis.

The determination of the tumour diameter in small intestine GIST cases is valuable in terms of predicting the clinical course and prognosis of the disease and making a risk classification. ${ }^{7,8}$ Liao et al. and Crosby et al. reported a mean tumour diameter of $4.7 \mathrm{~cm}$ and $11 \mathrm{~cm}$, respectively in small intestine GIST cases. ${ }^{13,15}$ In the present study, the mean tumour diameter was found to be $8.3 \pm 4.6 \mathrm{~cm}$. In the literature, a significant number of patients (30-51\%) have been reported as having a tumour over $10 \mathrm{~cm}$ in diameter. ${ }^{14,15}$ Similarly, in the present study, the rate of patients with a tumour diameter over $10 \mathrm{~cm}$ was found to be high $(61.5 \%)$. Crosby et al. reported that tumour diameter did not affect prognosis in their analysis. ${ }^{15}$ Similarly, wu et al. could not find a relationship between tumour diameter and mean OS and DFS. ${ }^{18}$ However, Liao et al. reported that a tumour diameter over $7 \mathrm{~cm}$ increased the recurrence rate in small intestine GIST cases. ${ }^{13}$ On the other hand, Huang et al. also found that the rate of recurrence was higher in patients with a tumour diameter of $10 \mathrm{~cm}$ or above. ${ }^{14}$ In the present study, the distribution rates of the tumour diameters were found to be similar between the patients who died and those survived.

In the correlation analysis performed in the present study, no significant correlation was found between tumour diameter and OS, five-year OS, and five-year DFS values; however, it was found that the DFS duration decreased as the tumour diameter increased. In the present study, the OS rate, five-year OS rate, and the mean five-year OS and DFS values were all found to be similar between the tumour diameter groups. However, the DFS was significantly lower in the patients with a tumour diameter $>5 \mathrm{~cm}$. In addition, it was determined that those with a tumour diameter $>5 \mathrm{~cm}$ had a 1.961-fold increased mortality risk. These findings show that tumour diameter is important in terms of prognosis in small intestine GIST cases but that tumour diameter alone may not provide accurate and sufficient data for predicting a prognosis.

The determination of mitotic activity in the primary tumour in small intestine GIST cases is also valuable in terms of predicting the clinical course and prognosis of the disease and making a risk classification. ${ }^{7,8}$ Liao et al. reported the rate of the patients with a mitotic index of 5/50 HPF and below as $69.5 \% .{ }^{13}$ In the present study, $61.5 \%$ of the patients had a mitotic index of 5/50 HPF and below. Crosby et al. reported that the mitotic index did not affect prognosis; ${ }^{15}$ however, Liao et al. and Huang et al. reported that the recurrence rate of those with a mitotic index above 5/50 HPF was significantly higher than those with an index of 5/50 HPF or below. ${ }^{13,14}$ Huang et al. reported that those with a mitotic index higher than 5/50 HPF had a 5.2-fold increased risk of recurrence and that there was a significant relationship between the mitotic index and mortality. ${ }^{14}$ In the present study, the mitotic index distributions were similar between the patients who died and those who survived. Correlation analysis of the patients did not reveal any significant correlations between the mitotic index value and the OS, DFS, five-year OS, and five-year DFS values. Wu et al. reported that the mitotic index significantly affected the mean OS and DFS durations. ${ }^{18}$ In the present study, the OS rate, DFS rate, five-year OS rate, and the mean five-year OS and DFS durations were all similar among the mitotic index groups. All these findings show that the mitotic activity level in the primary tumour is important in terms of prognosis and mortality but that the mitotic index alone may not be sufficient in predicting prognosis.

When the tumour location, tumour diameter, and mitotic index are evaluated together, a risk classification can be made to predict the development of metastasis or recurrence in GIST cases. ${ }^{3,7,8}$ In the present study, $67.5 \%$ of the patients were in the high-risk group. Huang et al. determined that the rate of recurrence was higher in the high-risk group patients in their study. ${ }^{14}$ In the present study, the 
levels of risk between the groups were found to be similar between the patients who died and those who survived. However, it was determined that the patients in the high-risk group had a 1.961-fold increased risk of mortality. In the present study, the OS rate, five-year OS rate, and mean fiveyear OS and DFS durations were all similar among the risk groups, but the mean DFS duration was found to be significantly lower in those in the high-risk category. In the present study, it was also found that the risk level category and the DFS were significantly inversely correlated. These findings show that risk classification is critical in small intestine GIST cases and that high-risk group patients should be closely monitored in terms of the development of recurrence or metastasis.

There were some limitations in the present study. Firstly, it is a single-centred and retrospective nature. Secondly, the inclusion of patients in the study whose five-year follow-up period was not completed might have caused low mean OS and DFS durations. So, the five-year OS and five-year DFS were also used in addition to general OS and DFS to reduce the effect of this situation.

\section{CONCLUSION}

The OS ratio and OS duration were not as high as expected in small intestine GIST cases. In addition, tumour diameter, mitotic index and risk classification may not provide sufficient information in terms of predicting the prognosis in some cases. Finally, the frequency of recurrence and/or metastasis is higher than expected - although complete resection is achieved, and its negative effect on survival indicated the importance of close follow-up.

\section{ETHICAL APPROVAL:}

This study was performed in line with the principles of the Declaration of Helsinki. Ethical approval was waived by the local Ethics Committee in view of the retrospective nature of the study and all the procedures being performed were part of the routine care (Date: 08/07/2020; No. 2020/514/ $181 / 12$ ).

\section{PATIENTS' CONSENT:}

No informed consents were taken from the patients since the data were collected from the hospital records retrospectively and since no private information was given in the paper.

\section{CONFLICT OF INTEREST:}

The authors declared no conflict of interest.

\section{AUTHORS' CONTRIBUTION:}

HU: Conception and design, analysis and interpretation of data, drafting of the manuscript, advices and final approval. YT: Analysis and interpretation of data, conception and design, reviewing the paper, and final approval.

OA: Acquisition of data, analysis and interpretation of data, reviewing the paper, and final approval.

BB: Analysis and interpretation of data, reviewing the paper, and final approval.

\section{REFERENCES}

1. Grover S, Ashley SW, Raut CP. Small intestine gastrointestinal stromal tumours. Curr Opin Gastroenterol 2012; 28(2):113-23. doi: 10.1097/MOG.0b013e32834ec154.

2. Søreide K, Sandvik OM, Søreide JA, Giljaca V, Jureckova A, Bulusu VR. Global epidemiology of gastrointestinal stromal tumours (GIST): A systematic review of population-based cohort studies. Cancer Epidemiol 2016; 40:39-46. doi: 10.1016/j.canep.2015.10.031.

3. Joensuu H, Hohenberger P, Corless CL. Gastrointestinal stromal tumour. Lancet 2013; 382(9896):973-83. doi: 10.1016/S0140-6736(13)60106-3.

4. Miettinen M, Lasota J. Gastrointestinal stromal tumours: Pathology and prognosis at different sites. Semin Diagn Pathol 2006; 23(2):70-83. doi: 10.1053/j.semdp.2006. 09.001.

5. Akahoshi K, Oya M, Koga T, Shiratsuchi Y. Current clinical management of gastrointestinal stromal tumour. World J Gastroenterol 2018; 24(26):2806-17. doi: 10.3748/wjg. v24.i26.2806.

6. Keung EZ, Raut CP. Management of gastrointestinal stromal tumours. Surg Clin North Am 2017; 97(2):437-52.

7. Miettinen M, Makhlouf $H$, Sobin LH, Lasota J. Gastrointestinal stromal tumours of the jejunum and ileum: A clinicopathologic, immunohistochemical, and molecular genetic study of 906 cases before imatinib with long-term follow-up. Am J Surg Pathol 2006; 30(4):477-89. doi: 10.1097/00000478200604000-00008.

8. Fletcher CD, Berman JJ, Corless C, Gorstein F, Lasota J, Longley BJ, et al. Diagnosis of gastrointestinal stromal tumours: A consensus approach. Hum Pathol 2002; 33(5):459-65. doi: 10.1053/hupa.2002.123545.

9. Nishida T, Goto O, Raut CP, Yahagi N. Diagnostic and treatment strategy for small gastrointestinal stromal tumours. Cancer 2016; 122(20):3110-8. doi: 10.1002/cncr.30239.

10. El-Menyar A, Mekkodathil A, Al-Thani H. Diagnosis and management of gastrointestinal stromal tumours: An up-to-date literature review. J Cancer Res Ther 2017; 13(6): 889-900. doi: 10.4103/0973-1482.177499.

11. Florou V, Wilky BA, Trent JC. Latest advances in adult gastrointestinal stromal tumours. Future Oncol 2017; 13(24):2183-93. doi: 10.2217/fon-2017-0245.

12. Giuliano K, Ejaz A, Reames BN, Choi WS, Sham J, Gage M, et al. Comparing the long-term outcomes among patients with stomach and small intestine gastrointestinal stromal tumours: An analysis of the National Cancer Database. J Surg Oncol 2018; 118(3):486-92. doi: 10.1002/jso.25172.

13. Liao CH, Yeh CN, Wang SY, Fu CY, Tsai CY, Liu YY, et al. Surgical option for intestinal gastrointestinal stromal tumours-perioperative and oncological outcomes of laparoscopic surgery. Anticancer Res 2015; 35(2):1033-40.

14. Huang CC, Yang CY, Lai IR, Chen CN, Lee PH, Lin MT. 
Gastrointestinal stromal tumour of the small intestine: A clinicopathologic study of 70 cases in the postimatinib era. World J Surg 2009; 33(4):828-34. doi: 10.1007/s00268009-9918-4.

15. Crosby JA, Catton CN, Davis A, O'Sullivan B, Kandel R, Swallow $\mathrm{C}$, et al. Malignant gastrointestinal stromal tumours of the small intestine: A review of 50 cases from a prospective database. Ann Surg Oncol 2001; 8(1):50-9. doi: 10.1007/s10434-001-0050-4.

16. Bucher $\mathrm{P}$, Taylor S, Villiger $\mathrm{P}$, Morel P, Brundler MA. Are there any prognostic factors for small intestinal stromal tumours? Am J Surg 2004; 187(6):761-6. doi: 10.1016/j.amjsurg.2003.09.010.

17. Fan R, Zhong J, Wang ZT, Yu LF, Tang YH, Hu WG, et al. Prognostic factors and outcome of resected patients with gastrointestinal stromal tumours of small intestine. Med
Oncol 2011; 28(Suppl 1):S185-8.

18. Wu TJ, Lee LY, Yeh CN, Wu PN, Chao TC, Hwang TL, et al. Surgical treatment and prognostic analysis for gastrointestinal stromal tumours (GISTs) of the small intestine: Before the era of imatinib mesylate. BMC Gastroenterol 2006; 6:29. doi: 10.1186/1471-230X-6-29.

19. Tasci HI, Tekin A, Gündes E, Cakir M, Esen HH. Gastrointestinal stromal tumours of the small intestine in emergency surgery. Genel Tip Derg 2012; 22(4):125-9.

20. Machairas A, Karamitopoulou E, Tsapralis D, Karatzas T, Machairas N, Misiakos EP. Gastrointestinal stromal tumours (GISTs): An updated experience. Dig Dis Sci 2010; 55(12):3315-27. doi: 10.1007/s10620-010-1360-9.

21. Hatipoğlu E, Demiryas S. Gastrointestinal stromal tumours: 16 years' experience within a university hospital. Rev Esp Enferm Dig 2018; 110(6):358-64. doi: 10.17235/reed. 2018.5199/2017. 